\title{
Relationship for the Concentration of Dissolved Organic Matter from Corn Straw with Absorbance by using UV-Visible Spectrophotometer
}

\author{
Shamshad Khan', Wu Yaoguo', Zhang Xiaoyan', Xu Youning², Zhang Jianghua' ${ }^{2}$, Hu Sihai' \\ ${ }^{1}$ Department of Applied Chemistry, School of Science, \\ Northwestern Polytechnical University, Xi'an, 710072, China \\ shamshadkhan768@yahoo.com;wuygal@nwpu.edu.cn \\ 2Xi'an Institute of Geology and Mineral Resources, Xi'an, 710054, China
}

\begin{abstract}
A$ rapid technique to estimate the concentration of dissolved organic matter from corn straw using the UV-visible spectrophotometer was developed in this study. We tested samples and suitable relationship for the concentration of dissolved organic matter (DOM) with absorbance. The results demonstrated that the relationship between absorbance (254nm) and concentration of DOM is good surrogate to estimate the concentration of the DOM from corn straw. Absorption of DOM verified that it doesn't depend on $\mathrm{pH}$ in normal working range. Relatively, this method is very less time consuming, and low cost than the Chemical oxygen demand method and TOC-analyzer method. The absorbance (254nm) with concentration of DOM has linear relationship with high correlation $\left(R^{2}=0.998\right)$. It is suggested that the absorbance (254nm) should be used as a surrogate for concentration of DOM from corn straw.
\end{abstract}

Keywords: absorbance, chemical oxygen demand, corn straw, dissolved organic matter, concentration.

(C) Copyright 2014 Authors - This is an Open Access article published under the Creative Commons Attribution License terms http://creativecommons.org/licenses/by/3.0. Unrestricted use, distribution, and reproduction in any medium are permitted, provided the original work is properly cited.

\section{Introduction}

Dissolved organic matter is a complex heterogeneous mixture of organic compounds containing the carboxylic, carbonyl, methoxyl, hydroxyl, and phenolic functional groups and the major source of these organic matters are living organisms deposited on or within soil components that play significant role in plant nutrition and soil environments [1]. If soil contains the sufficient amount of organic matter, there the plants grow are better, produce higher yields; and the nutritional quality of harvested foods and feeds are greater. During the last decay dissolved organic matter is become key parameter in agriculture and environmental fields because of its involvement in mobilization and transportation of acidty, colloids, nutrients, metals and pollutants and serves as a substrate for microbial growth [2-6]. Although various literatures have been considered to the consequence of DOM on the plants and soil environment, but not many study are available on characterization of DOM in water. Primary compositions of elements in DOM are carbon (52-56\%), hydrogen (4-5.5\%), oxygen (33-39\%), and small fractions of sulfur, nitrogen, and phosphorus [7]. Christman et al. [8] were suggested the hypothetical structures for DOM on degradation of the products. However, it is difficult to describe the specific chemical structure of DOM due to its heterogeneous organic matter characters.

Yet now, there is no direct method is accessible to estimate the concentration of DOM in water because of its highly complicated structures [8,9]. Two of the most widely used methods to surrogate the concentration of DOM are the total organic carbon analyzer (TOC) and Chemical oxygen demand methods. Previous method estimates the concentration of organic carbon content in water which proxy the concentration of DOM. Afterward estimates the quantity of oxygen required to oxidize the organic materials which indicate the organic matter in water. But such methods required the much time, expensive chemicals, sophisticated instrument 
and require a large sample volume for the analysis of concentration of DOM of each sample. These shortcomings have lead to the improvement of spectroscopic methods towards the quantification of DOM concentration.

Ultraviolet (UV) absorption spectrophotometer is generally used to study various properties of the DOC, such as its aromaticity, hydrophobic content, and biodegradability [2,10-12] because DOM have constitute such type of components which have capacity to absorb the ultraviolet light for example unsaturated aliphatic bonds and benzenoid type components $[13,14]$. Specific absorbance at different specific wavelengths has been used to measure the aromaticity, hydrophobic content, apparent molecular weight and size, and biodegradability [15-18].UV-absorbance is good surrogate the concentration of DOM specifically concentration of aromaticity in DOM at $254 \mathrm{~nm}$ absorbance [13,18]. Anton et al. [19] reported that UVabsorbance showed much closed linear relationship (0.99) between concentration of DOM and UV-254 absorbance in throughfall and soil solution samples. Aromaticity fraction in DOM is surrogate to estimate dissolved organic matter by using absorbance $254 \mathrm{~nm}$ because of the absorbance of organic solutes is directly proportional to their concentration of aromatic compounds [20].This correlation was considered here to develop the relationship for concentrations of DOM in water extracted from corn straw and absorbance.

Based on the above discussion, absorbance of a water sample at specific wavelength $254 \mathrm{~nm}$ is good proxy to the concentration of DOM. Standard calibration curve should be able to indicate the total concentration of DOM from corn straw with absorbance $254 \mathrm{~nm}$. Thus the aim of this study to establish relationship between absorbance $254 \mathrm{~nm}$ and concentration of DOM from corn straw by using UV-visible spectrophotometer should be able to surrogate the concentration of DOM from corn straw. We will also demonstrate the effect of $\mathrm{pH}$ on absorbance at $254 \mathrm{~nm}$.

\section{Material and Methods}

Corn Straw is used as source of DOM in water. Extractions of DOM from corn straw just carried out by follow the method mentioned by Zhongqi et al.[6,21]. In concise, initially corn straw air-dried, and ground to pass through a 1-mm sieve. Just before the absorbance experiments, mix with 40:1 (v/w) water to sample proportion using cold water, periodic shaking it $18 \mathrm{~h}$, suspension were centrifuged $(900 \times \mathrm{g})$ for $30 \mathrm{~min}$ and filtered through $0.45-\mu \mathrm{m}$ pore size polycarbonate filters. Aliquots of water samples of corn straw were analyzed with total carbon analyzer (Shimadzu TOC $5000 \mathrm{~A}$ ) after filtration through $0.45-\mu \mathrm{m}$ pore size polycarbonate filters. Stock solution of $563.8 \mathrm{mg} \mathrm{L}^{-1}$ DOM was used to prepare the standard solutions containing different amount of dissolved organic matter. UV-visible absorbance measurements were performed on a high precision, double-beam spectrophotometer (model 2550) between 220 and $450 \mathrm{~nm}$ with the reference of distilled water. A quartz cell with $1.0 \mathrm{~cm}$ path length was used. Buffer solutions to maintain $\mathrm{pH}$ were not need because a set of $5 \mathrm{mg} \mathrm{L}^{-1}$ of DOM solutions prepared at different $\mathrm{pH}$ have demonstrated that UV-visible spectra were not significantly affected by the 4 to 10 range of $\mathrm{pH}$ as shown in Figure 1. The negligible effect of $\mathrm{pH}$ on the DOM samples presented in this study is less than observed for soil humic substances [22]. This result also is in agreement of the observed result of Wang and Hsieh who reported that humic acids solutions prepared at different $\mathrm{pH}$ have showed that the UVvisible spectra were not affected by the $\mathrm{pH}$ at the normal working range. The minute dependency of UV absorbance on $\mathrm{pH}$ in the range of 4-10 means that, within this $\mathrm{pH}$ range, it is unnecessary to adjust the $\mathrm{pH}$ to a constant value to compare results between samples.

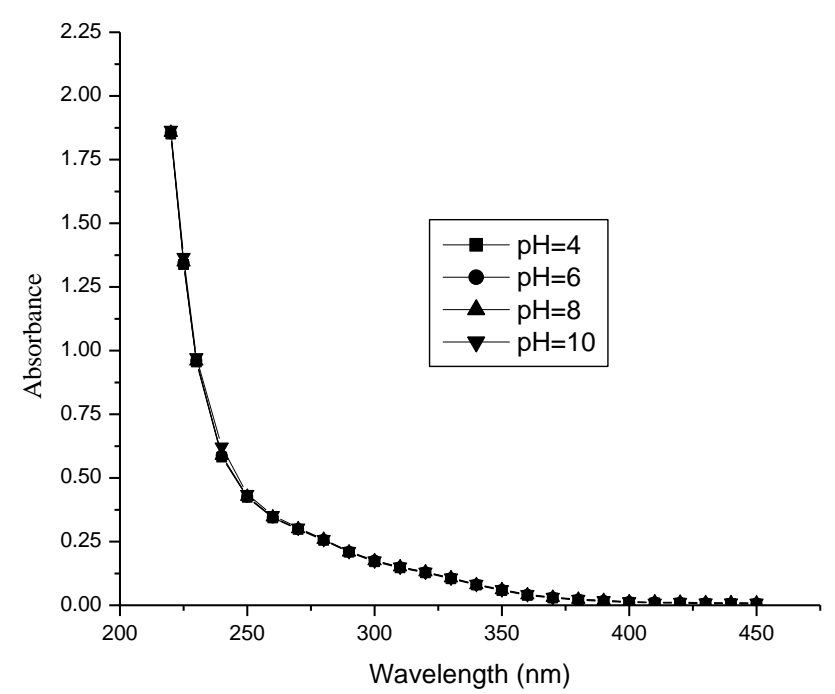

Figure 1. Effect of pH on UV-visible spectra of $5 \mathrm{mg} \mathrm{L}^{-1}$ of dissolved organic matter in water from corn straw.

\section{Results and Discussion}

As can be seen from figure 2, that absorbance increases with increasing the concentrations of DOM. 
The absorbance at wavelength length less than $280 \mathrm{~nm}$ is much greater than that of longer wavelength as a result a perfect slope is obtained at the shorter wavelength $(<285 \mathrm{~nm})$, when concentration of DOM is higher than this trend is much more visible as seen in the spectra. The absorbance measured at greater wavelength $(>400 \mathrm{~nm})$ is comparatively less than that absorbance at $280-400 \mathrm{~nm}$.This result almost agrees with the experimental results of Wang and Hsieh [23], who reported that the absorbance of humic acids at wavelength length less than $250 \mathrm{~nm}$ is causes a sharp slope at the longer wavelength $(<300)$, and absorbance at longer wavelength $(>400 \mathrm{~nm})$ is relatively low as compared with those observed at UV and sub-UV ranges $(200-400 \mathrm{~nm})$.

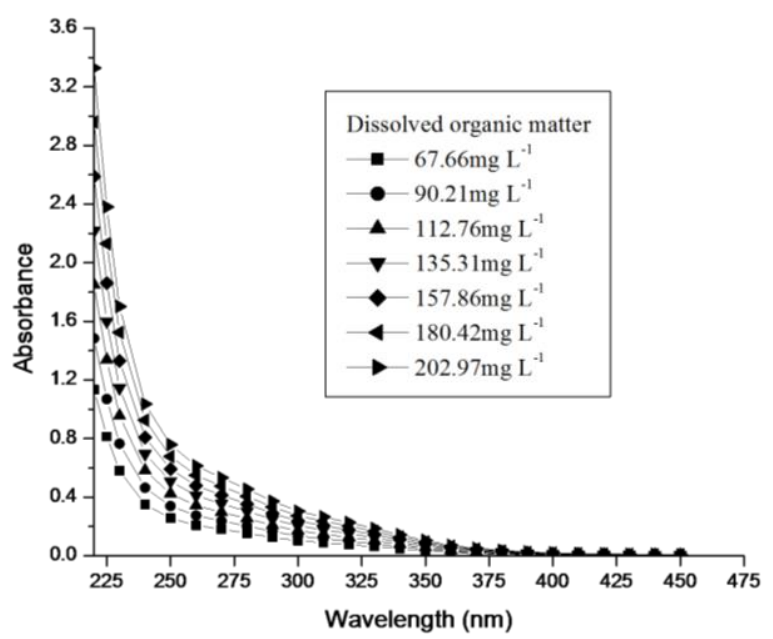

Figure 2. UV-visible spectra of different concentrations of dissolved organic matter in water from corn straw.

For the validation of these experimental results (Figure 2), it should follow Beer-Lambert law because Beer-Lambert law is independent of wavelength. The Beer-Lambert law has been examined at wavelengths $220,240,250,280,290,300,310,320,330,340,350,360,37$ $0,380,390,400,430,450 \mathrm{~nm}$ which showed the linearity with correlation coefficients $\left(\mathrm{R}^{2}\right)$ greater than 0.99 . It implies that Beer-Lambert law is applicable between range of $220-450 \mathrm{~nm}$ as shown in figure 3.

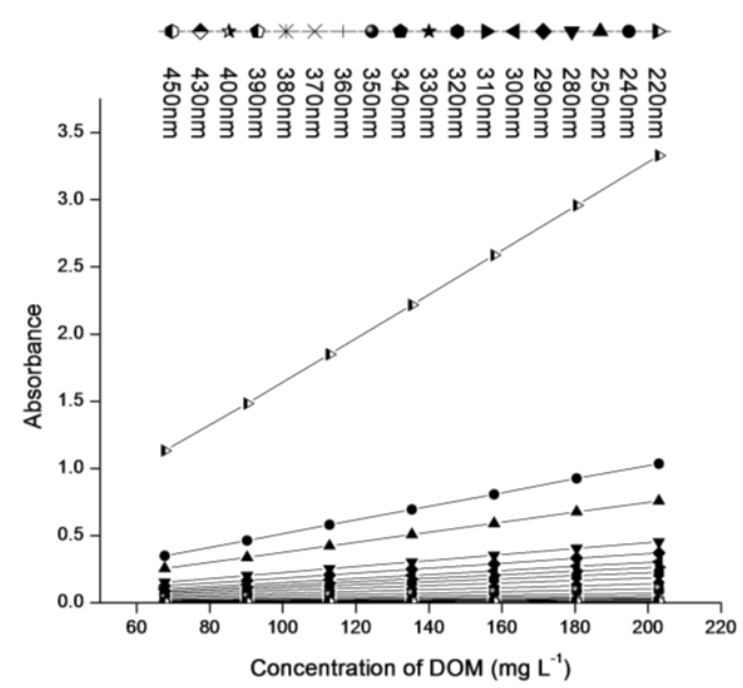

Figure 3. UV-visible spectra of different concentrations of dissolved organic matter in water from corn straw for verification of Beer-Lambert law.

In order to justify the UV method, we developed the relation between the absorbance at $254 \mathrm{~nm}$ and various concentrations of DOM determined by carbon analyzer. As shown in figure 4, the relationship between the absorbance $(254 \mathrm{~nm})$ and concentration of DOM, the UV absorbance at $254 \mathrm{~nm}$ is highly correlated $\left(\mathrm{R}^{2}\right.$ $=0.998 ; \quad \mathrm{P}<0.0001$ ) with concentration of DOM determined by carbon analyzer. So it is suggested that the absorbance at $254 \mathrm{~nm}$ should be used as a proxy for concentration of DOM from corn straw. Such correlation between absorbance and concentration of DOM determined by Huoliang et al [24] for the printing and dyeing waste water as shown in figure 4.

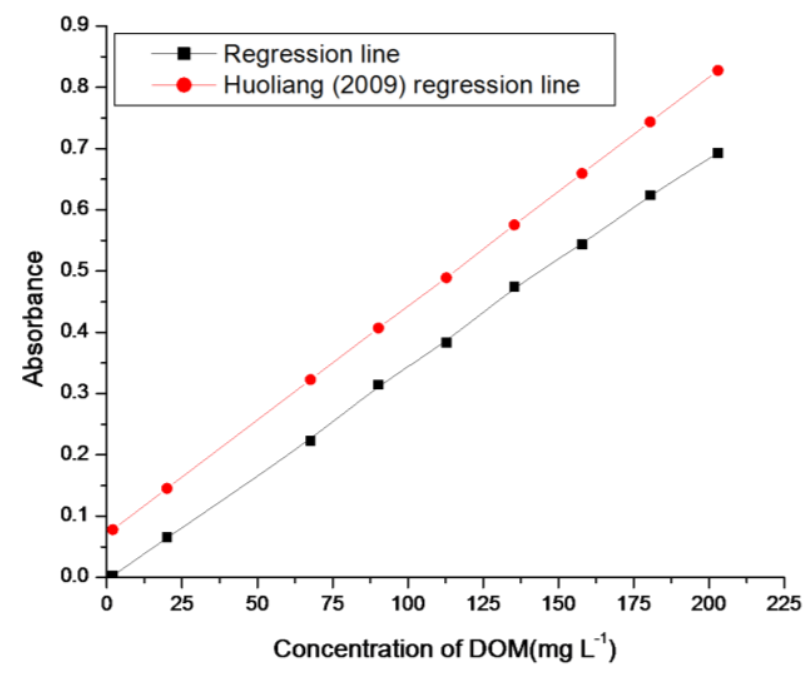

Figure 4. Correlation between absorbance at $254 \mathrm{~nm}$ and concentration of DOM determined by carbon analyzer method. 
The equation of the least squares regression line of figure 4 for corn samples is:

$$
\begin{aligned}
& \text { DOM }\left(\mathrm{mg} \mathrm{L}^{-1}\right)= \\
& \quad 288.078 \times \text { absorbance }(254 \mathrm{~nm})+1.3
\end{aligned}
$$

In the above equation $1,288.078$ and 1.3 are representing the slope and y-intercept respectively. The intercept of the regression line shows the presence of $1.3 \mathrm{mg} \mathrm{L}^{-1}$ of non-UV absorbing DOM, possibly due to the organic matter containing no chromophores absorbing at $254 \mathrm{~nm}$. These could include saturated aliphatic compounds, low molecular weight oily acids, or carbohydrates. Lower limit detection is a significant affecting factor on the precision and accuracy of the measure concentrations in analytical chemistry. We have calculated lower limit of detection $6.248 \times 10^{-5} \mathrm{mg} \mathrm{L}$ 1 from calibration graph of figure 4 by the following phenomena. The actual absorbance (response points) on Y- axis composing the line usually do not fall exactly on the line for the "fitting" of the calibration graph (Figure 4). Hence, random errors were implied. The parameters for calculating errors due to calibration graph in figure 4 using equation 1 are in shown table 1.

Table 1. Parameters for calculating errors due to calibration graph of figure 4 .

\begin{tabular}{|c|c|c|c|c|}
\hline $\mathrm{Xi}$ & $\mathrm{Yi}$ & $\mathrm{Yi}^{*}$ & $\left(\mathrm{Yi}^{-} \mathrm{Yi}^{*}\right)$ & $\left(\mathrm{Yi}^{-} \mathrm{Yi}^{*}\right)^{2}$ \\
\hline 2 & 0.0024 & 0.0024 & 0 & 0 \\
\hline 20 & 0.0650 & 0.0649 & 0.0001 & $1.0 \times 10^{-8}$ \\
\hline 67.66 & 0.2231 & 0.2303 & -0.0072 & $5.184 \times 10^{-5}$ \\
\hline 90.21 & 0.3145 & 0.3086 & 0.0059 & $3.481 \times 10^{-5}$ \\
\hline 112.76 & 0.3833 & 0.3869 & -0.0036 & $1.29 \times 10^{-5}$ \\
\hline 135.31 & 0.4750 & 0.4652 & 0.0098 & $9.60 \times 10^{-5}$ \\
\hline 157.86 & 0.5435 & 0.5435 & 0 & 0 \\
\hline 180.42 & 0.6241 & 0.6218 & 0.0023 & $5.29 \times 10^{-6}$ \\
\hline 202.97 & 0.6929 & 0.7000 & -0.0071 & $5.04 \times 10^{-5}$ \\
\hline$\sum\left(\mathrm{Yi}^{-} \mathrm{Yi}^{*}\right)^{2}=2.512 \times 10^{-4}$ \\
\hline
\end{tabular}

The standard error of the y-estimate was calculated by Equation 2.

$$
S y=\sqrt{\frac{\sum\left(Y i-Y i^{*}\right)^{2}}{n-2}}=0.006
$$

Where $\mathrm{Yi}^{*}$ is "fitted" $\mathrm{y}$-value for each $\mathrm{xi}$, (calculated from Eq. 1). Thus, Yi- Yi* is the vertical deviation of the found $y$-values from the line and " $n$ " is number of calibration points.

This uncertainty about the y-values (the fitted yvalues) is transferred to the corresponding concentrations of the unknowns on the x-axis and can be expressed by the standard deviation of the obtained $\mathrm{x}$-value. The exact calculation is rather complex but a workable approximation can be calculated with:

$$
S x=\frac{S y}{b}=2.083 \times 10^{-5}
$$

So Lower Limit of Detection derived from a calibration graph was calculated finally by using following equation:

$$
\mathrm{LLD}=3 \times \mathrm{Sx}=6.248 \times 10^{-5}
$$

This is very convenient and economical for determination of concentration of DOM from corn straw. Data presented in Figure 5 compare the values of concentrations of DOM estimated by TOC carbon analyzer and UV-visible spectrophotometer at $254 \mathrm{~nm}$. A strong linear correlation (R2>0.99) exists between these two methods.

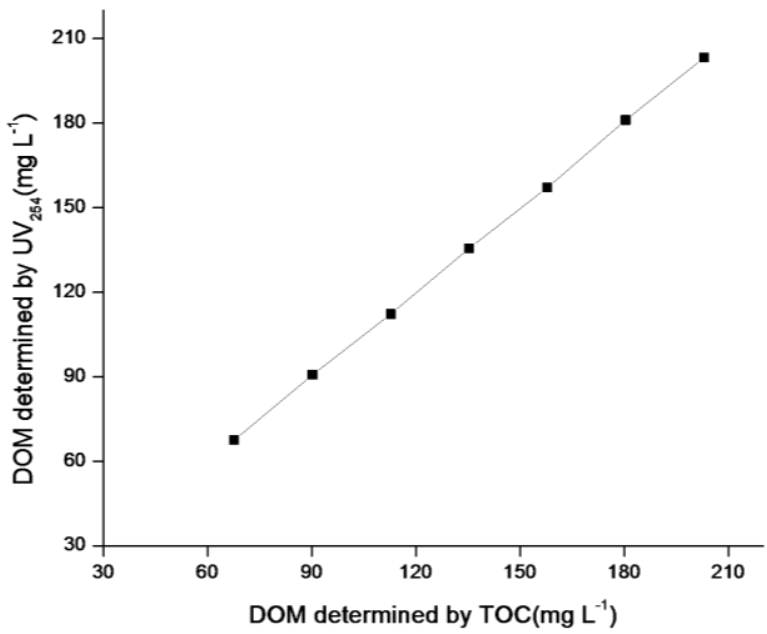

Figure 5. Correlation of the concentrations of DOM by UV 254 technique versus concentrations of DOM determined by the TOC carbon analyzer.

Other methods like Chemical oxygen method and TOC analyzer method are more expensive, time consuming and need of more sophisticated instrument but in this method no chemical is required and very commonly using device needed like UV-Visible 
Spectrophotometer. Another advantage is that in normal working range of $\mathrm{pH}$ no need to use buffer solutions because changes of $\mathrm{pH}$ within normal working ranges has no effect on this method.

\section{Conclusion}

A very highly linear correlationship $\left(\mathrm{R}^{2}=0.998\right)$ is illustrated between absorbance $(254 \mathrm{~nm})$ and concentration of DOM in water from corn straw. UVvisible spectrophotometer method is very straightforward, fast and low-priced alternative for assessment of DOM. This relation has advantage over common methods for estimation of DOM with less time consuming. It is also working well in normal working $\mathrm{pH}$ ranges $(4-10)$.

\section{Acknowledgements}

This work was supported by the Land and Resources Scientific Research of China from special fund (20111020) in the public interest, the project titled "survey and assessment of groundwater pollution in main cities of Northwestern China (1212011220982)" and "NPU Foundation for Fundamental Research (NPU-FFR-JCR20130145)”.

\section{References}

[1] H.O. Neung, A.P. Brian, A.M. Philip, J.H. Peter, M.B. Sandra, O. Noriaki, M.L. Kavvas, A.B. Brian, R.H. William "The role of irrigation runoff and winter rainfall on dissolved organic carbon loads in an agricultural watershed" Agriculture, Ecosystems and Environment, 179(1), 2013, pp.1-10.

[2] D. Jorg, K. Klaus "Estimation of the hydrophobic fraction of dissolved organic matter in water samples using UV photometry" Water Research, 36(20), 2002, pp. 5037-5044.

[3] R.M.W. Amon, R. Benner "Bacterial utilization of different size classes of dissolved organic matter" Limnology and Oceanography, 41(1), 1996, pp. 4151.

[4] A.L. Bonnie, M.C. Rose, S.W. Howard "Changes in dissolved organic matter fluorescence and disinfectionbyproduct formation from UV and subsequent chlorination/chloramination" Journal of Hazardous Materials, 264(1), 2014, pp. 411-419.

[5] G. Rachel, J.H. Peter, W. Naomi, F. Christopher "Dissolved organic carbon and trihalomethane precursor removal at a UK upland water treatment works" Science of the Total Environment. 468469(1), 2014, pp.228-239.
[6] K. Shamshad, W. Yaoguo, Z. Xiaoyan, H. Sihai, L. Tao, F. Yilin, L. Qiuge "Influence of dissolved organic matter from corn straw on $\mathrm{Zn}$ and $\mathrm{Cu}$ sorption to Chinese loess" Toxicological \& Environmental Chemistry, 95(8), 2013, pp.1318-1327.

[7] D.A. Reckhow, P.C. Singer, R.L. Malcolm "Chlorination of humic materials: by product formation and chemical interpretations" Environmental science \&technology, 24(11), 1990, pp. $1655-1664$.

[8] R.F. Christman, D.L. Norwood, Y. Seo, F.H. Frimmel "Humic substances: II. In search of structure" In: Hayes, M.H.B., Mac-Carty, P., Malcolm, R.L., Swift, R.S. (eds).Publishing Wiley, Chichester, England, 1985, pp. 451-463.

[9] G.G. Choudhry "Humic substances. structural, photophysical, photochemical and free radical aspects and interactions with environmental chemicals" Gordon \& Breach Publishers, New York, 1984, pp. 98-106.

[10] C.S. Uyguner, C. Hellriegel, W. Otto, C. Larive "Characterization of humic substances: Implications for trihalomethane formation" Analytical and Bioanalytical Chemistry, 378(6), 2004, pp.1579-1586.

[11] J.P. Croué, M.F. Benedetti, D. Violleau, J.A. Leenheer "Characterization and copper binding of humic and nonhumic organic matter isolated from the South Platte River: Evidence for the presence of nitrogenous binding site" Environmental Science \& Technology, 37(2), 2003, pp.328- 336.

[12] K. Hautala, J. Peuravuori, K. Pihlaja "Measurement of aquatic humus content by spectroscopic analyses" Water Research, 34(1), 2000, pp.246258.

[13] A.U. Eaes, P.R. Bloom "Fulvic acid ultravioletvisible spectra: Influence of solvent and $\mathrm{pH}^{\prime \prime}$ Soil Science Society of America Journal, 54(5), 1990, pp. 1248-1254.

[14] S.J. Traina, J. Novak, N.E. Smeck "An Ultraviolet Absorbance Method of Estimating the Percent Aromatic Carbon Content of Humic Acids" Journal of Environmental Quality, 19(1), 1990, pp.151-153.

[15] M. Simonsson, K. Kaiser, F. Andreux, J. Ranger "Estimating nitrate, dissolved organic carbon and DOC fractions in forest floor leachates using ultraviolet absorbance spectra and multivariate analysis" Geoderma.124, 2005, pp.157-168.

[16] K. Kalbitz, J. Schmerwitz, D. Schwesig, E. Matzner "Biodegradation of soil-derived dissolved organic 
matter as related to its properties" Geoderma, 113, 2003, pp.273-291.

[17] J. Peuravuori, K. Pihlaja "Molecular size distribution and spectroscopic properties of aquatic humic substances" Analytica Chimica Acta, 337 (20), 1997, pp.133-149.

[18] Y. Chin, A. George, E. O'Loughlin "Molecular Weight, Polydispersity, and Spectroscopic Properties of Aquatic Humic Substances" Environmental science \& technology, 28 (11), 1994, pp. 1853-1858.

[19] B. Anton, S.S. Ronald, M. Axel, W.W. Walter "Estimating dissolved organic carbon in natural waters by UV absorbance (254 nm)" Journal of Plant Nutrition and Soil Science, 159(6), 1996, pp.605-607.

[20] B.A. Bergamaschi, M.S. Fram, C. Kendall, S.R. Silva, G.R. Aiken, R. Fujii "Carbon isotope constraints on the contribution of plant material to the natural precursors of trihalomethanes" Organic Geochemistry, 30(8), 1999, pp. 835-842.

[21] H. Zhongqi, M. Jingdong, W.C. Honeycutt, O. Tsutomu, J.F. Hunt, J.C.M. Barbara "Characterization of plant-derived water extractable organic matter by multiple spectroscopic techniques" Biology and Fertility of Soils, 45(6), 2009, pp.609-616.

[22] P.R. Bloom, J. Leenheer "Vibrational, Electronic, and Highenergy Spectroscopic Methods for Characterizing Humic Substances" In Humic Substances II: In Search of Structure; Hayes, M. H. B., Malcolm, R., Swift, R. S., Eds.; John Wiley \& Sons: New York, 1989, Chapter 14, pp. 409-446.

[23] G. Wang, S. Hsieh, "Monitoring natural organic matter in water with scanning spectrophotometer" Environment International, 26 (4), 2001, pp. 205-212.

[24] K. Huoliang, W. Huifang "A Rapid Determination Method of Chemical Oxygen Demand in Printing and Dyeing Wastewater Using Ultraviolet Spectroscopy" Water Environment Research, 81(11), 2009, pp. 2381-2386. 